\title{
Evaluación, Física, Química y Biológica de compostas tipo bocashi elaboradas con estiércol de bovino, ovino, cerdo y conejo más una vermicomposta
}

\section{Physical, Chemical and Biological evaluation, type of bocashi compostas elaborated with bovine, sheep, pig and rabbit stretcher plus one vermicomposta}

\author{
DE LUNA-VEGA, Alicia*†, GARCÍA-SAHAGÚN, María Luisa, PIMIENTA-BARRIOS, Enrique y \\ RODRÍGUEZ-GUZMÁN, Eduardo
}

\author{
Universidad de Guadalajara. Centro Universitario de Ciencias Biológicas y agropecuarias`(CUCBA).Camino Ramón \\ Padilla Sánchez 2100 Nextipac, 44600 Zapopan Jalisco
}

ID $1^{\text {er }}$ Autor: Alicia, De Luna-Vega

ID $1^{\text {er }}$ Coautor: María Luisa, García-Sahagún

ID $2^{\text {do }}$ Coautor: Enrique, Pimienta-Barrios

ID $3^{\text {er }}$ Coautor: Eduardo, Rodríguez-Guzmán

DOI: $10.35429 /$ JCPE.2019.20.6.33.40

\section{Resumen}

Algunas compostas pueden producir fitotoxinas que inhiben el desarrollo de las plantas y la absorción de nutrientes por un exceso del ácido indolacético si la composta no está madura. En el presente trabajo se plantea como objetivo: Evaluar la calidad de la composta mediante pruebas directas de fitotoxicidad y de calidad agronómica con las diferentes compostas. Para determinar la calidad como abono orgánico de la composta y vermicomposta, se plantearon las variables físicas, químicas y biológicas de acuerdo a los manuales ya existentes. Los resultados obtenidos para estas variables fueron: En las variables físicas químicas y biológicas se cumplen con todos los parámetros de acuerdo a la norma. La germinación de las semillas de las hortalizas se incrementó con respecto al testigo en un $14.93 \%$, posiblemente por la presencia de alguna sustancia promotora del desarrollo radicular encontrado en las compostas. Con respecto a la sobrevivencia el testigo fue inferior en un $3.08 \%$. Si bien la cantidad de nutrientes encontrados en la composta no son tan altos, estos cumplen con los requerimientos mínimos de las normativas para ser utilizado como sustrato en aplicaciones hortícolas. Conclusión, los resultados de este estudio indican que la composta elaborada con cualquier tipo de residuo se puede utilizar como sustrato en semilleros de chile, cebolla o de otras hortalizas para inducir la germinación y acelerar el desarrollo de las plantas

\begin{abstract}
Some composts can produce phytotoxins that inhibit the development of plants and the absorption of nutrients by an excess of indoleacetic acid if the compost is not mature. In the present work, the objective is to evaluate the quality of the compost by means of direct tests of phytotoxicity and agronomic quality with different composts. To determine the quality as organic compost and vermicompost fertilizer were considered physical, chemical and biological variables according to existing manuals. The results obtained for these variables were: In the physical, chemical and biological variables, all the parameters are fulfilled according to the norm. Seed germination of vegetables increased with respect to the control in $14.93 \%$, possibly due to the presence of some root development promoter found in the compost. With regard to survival the witness was inferior by $3.08 \%$ Although the amount of nutrients found in composts are not so high, they comply with the minimum requirements of the regulations to be used as a substrate in horticultural applications. Conclusion, the results of this study indicate that the compost elaborated with any type of residue can be used as a substrate in seedbeds of chili, onion or other vegetables to induce germination and accelerate the development of plants.
\end{abstract}

Organic Production, Substrate, Phytotoxicity

Citación: DE LUNA-VEGA, Alicia, GARCÍA-SAHAGÚN, María Luisa, PIMIENTA-BARRIOS, Enrique y RODRÍGUEZ-GUZMÁN, Eduardo. Evaluación, Física, Química y Biológica de compostas tipo bocashi elaboradas con estiércol de bovino, ovino, cerdo y conejo más una vermicomposta. Revista de Energía Química y Física. 2019. 6-20: 33-40

\footnotetext{
* Correspondencia al Autor (Correo electrónico: dva20851 @ cucba.udg.mx)

$\dagger$ Investigador contribuyendo como primer Autor
} 


\section{Introducción}

El manejo del suelo debe mejorar la fertilidad del mismo, de manera que puedan aumentarse después las producciones de los cultivos. Un suelo fértil es capaz de resistir la erosión y satisfacer las necesidades del cultivo en términos de humedad, aire, nutrientes, acidez y temperatura. La fertilidad se consigue mediante un amplio rango de prácticas agrícolas, todas las cuales contribuyen a mantener o aumentar la cantidad de materia orgánica en el suelo (Dalzel, 1991). Una forma de recuperar el potencial productivo del suelo, es a través de la aplicación de la materia orgánica, ya sea en forma de composta, vermiabono, etc., ya que proporciona y mejora las condiciones de fertilidad, estructura, $\mathrm{pH}$, mayor capacidad de retención de agua y nutrientes (De Luna y Vázquez, 2014).

El compostaje intenta recrear las condiciones que existirían en un ecosistema sin perturbar donde la materia orgánica se acumula en la superficie del suelo y no se incorpora regularmente a él como ocurre en los ecosistemas agrícolas (Lampkin, 1998).

El compostaje es la descomposición o degradación de los materiales de desechos orgánicos por una población mixta de microorganismos en un ambiente cálido, húmedo y aireado (Dalzel, 1991). El compostaje es un proceso complejo en el que intervienen una amplia gama de microorganismos que atacan a los residuos orgánicos. Los principales microorganismos responsables del proceso de compostaje son hongos, actinomicetos y bacterias y posiblemente, protozoos y algas (Simpson, 1991).

De acuerdo con Labrador (2002) en líneas generales, el compostaje es un proceso bioxidativo y controlado, en el que intervienen una gran diversidad de microorganismos, que requieren una humedad adecuada y sustratos orgánicos heterogéneos en su composición y homogéneos en cuanto a su tamaño y básicamente en estado solidó, y que pasa por una fase termofílica, dando al final como producto de los diferentes procesos de transformación de dióxido de carbono, agua, minerales y materia orgánica estabilizada e higienizada, rica en poblaciones microbianas útiles, en sustancias húmicas y en bioactivadores de la fisiología vegetal.
Dalzel (1991) considera que la composta es esencialmente una reorganización biológica de la fracción del carbono de la materia orgánica. El material orgánico, bien de origen industrial, doméstico o agrícola, es una mezcla de azucares, proteínas, hemicelulosa, celulosa, lignina y minerales en un amplio rango de concentraciones. Las fracciones contenidas en el material vegetal dependerán de la edad de la planta, su tipo y medio ambiente. La materia verde fresca contiene muchas sustancias solubles en agua, proteínas y minerales.

A medida que las plantas envejecen, tienden a retornar los minerales del suelo y los compuestos de bajo peso molecular se convierten en compuestos poliméricos de alto peso molecular tales como las hemicelulosa, celulosa y lignina.

Los abonos orgánicos producen efectos benéficos a los cultivos, dependiendo de la naturaleza del abono, características del suelo, tipo de cultivo, periodicidad de la aplicación y cantidad del abono, entre otros. Por otra parte los fertilizantes químicos solo mejoran las propiedades químicas del suelo, que los coloca en desventaja sobre los orgánicos, desde el punto de vista del mantenimiento de las propiedades físicas del suelo. Para la recuperación de los suelos y la inocuidad de nuestros alimentos, la composta es el mejor abono que el hombre puede hacer y consiste en seguir el ejemplo de la naturaleza: a través de microorganismos (bacterias, virus, hongos, algas) y macrorganismos (hormigas, escarabajos, gusanos, lombrices, etc.), se lograra la revitalización de los residuos orgánicos para convertirlos en composta (Triano et al., 2005).

Los abonos orgánicos ayudan a modificar las condiciones físicas del suelo, al mejorar la capacidad de retención del agua, la aireación, el drenaje y la friabilidad; y el color oscuro de la materia orgánica indica que los suelos se calientan más de prisa y, por tanto, el aumento de la temperatura del suelo en ciertas estaciones del año (Lampkin, 1998).

Rodríguez y Córdova, 2006 refieren que la composta es un mejorador de suelo porque favorece el desarrollo de sus funciones: 
Favorece la aireación y la retención de humedad. Junto con las arcillas fomenta la formación de agregados más estables. En suelos arenosos ayuda a la retención del agua.

Mejora la estructura del suelo. Por esta característica y porque permite la absorción del agua, es un agente preventivo de la erosión.

Provee un medio donde infinidad de microorganismos se desenvuelven; algunos procesan los residuos para convertirlos en humus para aprovecharlo o generar alimento para otros. Es la "casa" del sistema vivo del suelo.

Favorece el almacenamiento de nutrimentos y su disponibilidad para los vegetales.

Durante el proceso de compostaje se produce una intensa competencia por el alimento entre los microorganismos: se generan antagonismos, se forman antibióticos y el montón es invadido por macrofauna (ácaros, hormigas, lombrices, etc.) que contribuyen a la descomposición mediante la maceración de las partículas finas (Lampkin, 1998).

\section{Objetivo}

En el siguiente trabajo se plantea como objetivo la determinación de la calidad como abono orgánico, de la composta producida a partir de la excreta de diferentes especies como son bovino, ovino, cerdo y conejo.

\section{Materiales y métodos}

El presente trabajo se llevó a cabo en el campo experimental, así como en el laboratorio de Agromicrobiología del Centro Universitario de Ciencias Biológicas y Agropecuarias (CUCBA) de la Universidad de Guadalajara. La elaboración de la composta se realizó utilizando $50 \mathrm{~kg}$ de estiércol de las diferentes especies utilizada, $50 \mathrm{~kg}$ de residuos de verdes $50 \mathrm{~kg}$ de rastrojo de maíz, $500 \mathrm{~g}$ de levadura para pan y $500 \mathrm{~g}$ de azúcar, estos ingredientes se pusieron a fermentar durante 21 días, la preparación consistió en construir un "montón" a partir de capas paralelas de cada uno de los materiales, se aplicó el agua y la mezcla de azúcar y levadura para humedecer sin provocar escurrimiento.
En los primeros tres días se mezcló el montón por la mañana y por la tarde y a partir del cuarto día, se volteó una sola vez. Finalmente, entre los 12 y 15 días el abono fermentado logró su maduración, su temperatura fue igual a la ambiental, adquiriendo un color gris claro, estaba seco y de consistencia suelta después se hicieron análisis.

\section{Tratamientos}

Los tratamientos estudiados se muestran en el Cuadro 1.

\begin{tabular}{|l|l|l|}
\hline Trata & Excreta & \multicolumn{1}{c|}{ Adicionada } \\
\hline 1 & Bovino & residuos vegetales secos y verdes \\
azúcar, levadura y agua
\end{tabular}

Cuadro 1 Tratamientos estudiados

\section{Variables estudiadas}

Para determinar la calidad como abono orgánico de la composta y vermicomposta, se plantearon las variables, físicas, químicas y biológicas.

Variables físicas se determinaron las siguientes mediciones según el manual de Fisher et al. (2003): a) Densidad aparente (gr. cm-3), b) Capacidad de absorción de agua (gr. cm-3), c) Capilaridad (gr. cm-3), d) Infiltración (min.).

Variables químicas cuantificadas en la composta, materia seca, $\mathrm{N}, \mathrm{P}, \mathrm{K}, \mathrm{Ca}, \mathrm{Mg}, \mathrm{Mn}$, $\mathrm{Na}, \mathrm{Fe}, \mathrm{Zi}, \mathrm{Bo}, \mathrm{CO}_{3}, \mathrm{SO}_{4} \mathrm{pH}$, conductividad eléctrica

Variables biológicas, El efecto de la composta, en forma sólida y como extracto, sobre el porcentaje de germinación de semillas de chile (Capsicum annuum) y cebolla (Allium cepa). La fitotóxicidad de la composta registrando la sobrevivencia y desarrollo de la lombriz de tierra roja californiana (Eisenia Foetida andrei)

El número de microorganismos como Unidades Formadoras de Colonias (UFC) presentes en la composta.

La actividad microbiana, a través de la evolución de $\mathrm{CO}_{2}$ 


\section{Desarrollo del experimento}

\section{Variables físicas}

Absorbencia. Se utilizaron $20 \mathrm{~g}$ de composta tamizada la que se depositó en un matraz de $500 \mathrm{~mL}$ de capacidad; se agregaron $100 \mathrm{~mL}$ de agua destilada. El matraz se agitó durante 15 minutos (en el agitador AROS 160). Transcurrido el tiempo de agitación se procedió a realizar el filtrado de las muestras depositando la suspensión en embudos con papel filtro, el filtrado se depositó en tubos de ensayo del que se tomaron $7 \mathrm{~mL}$. Se procedió a centrifugar el filtrado durante 30 minutos a $3000 \mathrm{rpm}$ (centrifuga Ultra 8-V). Transcurrido el tiempo de centrifugado las muestras se pasaron al espectrofotómetro y se tomó la lectura a $640 \mathrm{~nm}$. Una vez realizada la lectura se tomaron $1 \mathrm{ml}$. de cada una de las muestras y se vació dentro de una caja de petri con papel filtro para registrar el corrimiento de la mancha. La toma de muestras se realizó semanalmente.

Capacidad de absorción de agua. La determinación de la capacidad de absorción de agua se realizó en una maceta con capacidad de $300 \mathrm{ml}$ y se colocó sobre una palangana. La maceta se rellenó del sustrato hasta la marca $(250 \mathrm{ml})$ dejándola caer varias veces para comprimir y rellenando nuevamente hasta la marca, una vez nivelado el sustrato se pesó (peso seco), se agregó agua a la palangana hasta una altura poco menor a la altura de la maceta, se retiró la maceta una vez que la superficie del sustrato se observaba ligeramente cubierta de agua, se dejó escurrir toda el agua de la maceta y posteriormente se pesó (peso húmedo).

Capilaridad. Para determinar la capilaridad se utilizó una maceta de $300 \mathrm{ml}$ y se rellenó la maceta con composta hasta la marca ( $250 \mathrm{ml})$, se dejó caer varias veces y se volvió a rellenar hasta la marca, se registró su peso (peso seco), se agregó agua a la palangana $(3 \mathrm{~cm})$ y se depositó la maceta dentro, se retiró después de 15 min.; se dejó escurrir por 10 min.; y se pesó (peso húmedo).

Densidad aparente. Para la determinación de la densidad (peso/volumen) se utilizó una probeta de $500 \mathrm{ml}$ de capacidad, a la que se le registró el peso. El sustrato se depositó en la probeta hasta los $400 \mathrm{ml}$ y se pesó. Se agitó para disminuir el espacio vació y nivelar la superficie y leer el volumen compactado.
Velocidad de infiltración. Para la prueba de infiltración se utilizó una maceta de plástico de $300 \mathrm{ml}$ de capacidad. El sustrato se colocó en la maceta hasta los $250 \mathrm{ml}$ En una probeta se midieron $100 \mathrm{ml}$ de agua, la que se agregó a la maceta haciendo movimientos circulares. Se activó el cronometro al momento de la caída del agua y se detuvo hasta que ésta se filtró completamente en el sustrato.

Los resultados se registraron como el tiempo de infiltración de los $100 \mathrm{ml}$.

Variables químicas: Medición de $\mathrm{pH}$ y conductividad eléctrica (CE). Se pesó un frasco vacío y sin tapadera, se pesaron 20 gr. de sustrato y se depositaron en el frasco, se midieron $40 \mathrm{ml}$ de agua destilada en una probeta, se vació al recipiente y se cerró el frasco, se agito durante 10 minutos en el agitador (AROS 160). En la suspensión se determinó el $\mathrm{pH}$ y la CE con un equipo Hanna (H1-9810). Las demás variables químicas se determinaron de acuerdo a los manuales establecidos en el laboratorio de agromicrobiología.

Variables biológicas. La determinación de las variables biológicas en la composta se realizó para observar:

\section{El efecto de la composta, sobre el porcentaje de germinación de semillas de chile} (Capsicum annuum) y cebolla (Allium cepa)

Se realizó mediante un bioensayo de porcentaje de germinación y de sobrevivencia. Las pruebas de germinación de semilla y sobrevivencia se llevaron a cabo con semillas de cebolla y chile. Se colocaron 20 semillas de cada especie en cajas de Petri de $10 \mathrm{~cm}$ de diámetro, se colocaron $5 \mathrm{~mm}$ de composta. La composta fueron saturada mediante la adición de agua destilada, posteriormente se colocaron las semillas. Las cajas se mantuvieron en una incubadora a $28^{\circ} \mathrm{C}$ y en la obscuridad, hasta que se evalúo el porcentaje de germinación después de cuatro días. Posteriormente a los siete días se evalúo el porcentaje de sobrevivencia.

Conteo de microorganismos. Se cuantificaron las poblaciones de hongos, bacterias y actinomicetos. Los medios de cultivo utilizados fueron PDA, agar nutritivo y agar Czapek, respectivamente. 
El método utilizado fue el de diluciones decimales y vaciado en placa, según el manual de Valdés (1980). Se utilizaron $10 \mathrm{~g}$ de muestra tamizada de composta y se depositaron en un frasco de dilución el cual contenía $90 \mathrm{ml}$ de agua destilada. El frasco se agitó por cinco minutos y posteriormente se tomó $1 \mathrm{ml}$ de la suspensión para realizar diluciones decimales hasta $10-8$. Se tomaron $0.5 \mathrm{ml}$ de cada una de las diluciones correspondientes y se depositaron en cajas de Petri con los medios de cultivo correspondiente para cada tipo de microorganismo. Una vez depositada la muestra se extendió sobre la superficie. Las cajas de Petri se pusieron en incubadora (TERLAB D80) a $28^{\circ} \mathrm{C}$ y el conteo de microorganismos se realizó a los tres y seis días de efectuada la siembra.

Evolución de $\mathrm{CO}_{2}$. La estabilidad valorada por respirometría, sirve para valorar la estabilidad relativa de los compuestos orgánicos de $\mathrm{C}$ presentes en una composta. La medición de $\mathrm{O}_{2}$ y $\quad \mathrm{CO}_{2}$ de muestras de aire tomadas directamente de un montón en compostaje activo puede proporcionar datos para conocer las necesidades de aireación del montón (Haug, 1993). Los valores de $\mathrm{CO}_{2} \quad\left(\mathrm{mg} \quad \mathrm{CO}_{2}\right)$ se determinaron durante la fase mesofílica y de maduración de la pila. La producción de $\mathrm{CO}_{2}$ permaneció constante entre los 4 y $5 \mathrm{mg} /$ día (figura 5) con algunas variantes.

\section{Diseño experimental}

En las variables físicas y químicas no hubo repeticiones, por lo que los resultados se presentan en forma cuadros.

Para determinar la calidad como abono orgánico de la composta, se plantearon las variables físicas químicas y biológicas. El diseño experimental utilizado para ubicar y evaluar el efecto de los tratamientos sobre el porcentaje de germinación de semillas, fue el denominado bloque completo al azar, utilizando tres repeticiones. Los datos obtenidos en las diferentes variables, se sometieron al análisis de varianza y a la prueba de separación de medias denominada DMS P> 0.05 (Padrón, 2003; Reyes, 1999).

\section{Resultados y discusión}

Absorbencia, esta medición se determinó
durante todo el proceso de compostaje en las
porciones alta, media y base de la pila, el
resultado de estas condiciones se ilustra en la
figura 6. Aquí se puede observar como los
valores de absorbencia disminuye conforme
avanza el proceso de compostaje; esta tendencia
se presentó con una mínima variación en las
diferentes compostas. Esta tendencia se
menciona en la literatura como la adquisición de
una coloración marrón oscura, asociada a la
presencia de compuestos húmicos. Este
principio se hace evidente en la medida que los
valores de absorbencia descienden
drásticamente de 0.354 a 0.117 nm en un periodo
de 10 días. El decaimiento en los valores de
absorbencia fue más lento en los siguientes 12
días, hasta un nivel de 0.029 nm. Esto indica la
lenta acumulación se sustancias húmicas a partir
del inicio de la fase termófila del proceso de
compostaje.

Capacidad de absorción de agua, el ensayo para evaluar la utilización de la composta como medio de cultivo al aumentar la cantidad de agua neta disponible para las plantas y reducir la frecuencia del riego. El cuadro 2 muestra una capacidad de absorción de agua con un valor de $41.6 \%$ en la composta en fase de maduración, siendo este un porcentaje superior al optimo que oscila entre el $20 \%$ y el $30 \%$ (Ansorena, 1994; Cadahia, 2005).

Capilaridad, esta propiedad consiste en que el sustrato tenga la capacidad de absorber agua a través de los microporos y de transportarla en todas las direcciones. Cuando el sustrato no tiene capilaridad, el agua se mueve verticalmente a través del perfil del mismo, llegando rápidamente al drenaje y dejando zonas secas en las cuales no se pueden desarrollar las raíces (Cadahia, 2005).

Densidad, la densidad aparente representa el peso seco del medio con relación al volumen total que ocupa. Conforme aumenta la densidad aparente, las condiciones del drenaje y la porosidad para el aire disminuyen. Es necesario que el compost este formado por partículas de tamaño adecuado a su utilización, como sustratos para macetas sin suelo y otras importantes aplicaciones. El cuadro 2, muestra la densidad aparente de la composta la cual según los parámetros presenta un valor aceptable para ser utilizado como sustrato de crecimiento. 
Infiltración, la Infiltración al ser la penetración de agua en el suelo determina la cantidad de agua de escurrimiento superficial y con ello, el peligro de erosión, determinando los tiempos de riego y los volúmenes de agua a utilizar. En el cuadro 12, se presenta la velocidad de infiltración de la composta la cual se expresa como el tiempo (en minutos) necesario para que se absorba, a través de la superficie de una muestra de sustrato seco. El nivel óptimo es igual o inferior a 5 minutos (Cadahia, 2005).

\begin{tabular}{|c|c|c|c|c|c|}
\hline & Bovinos & Cerdos & Ovinos & Conejos & $\begin{array}{c}\text { Vermi } \\
\text { composta }\end{array}$ \\
\hline \multicolumn{6}{|l|}{ Absorbencia } \\
\hline $\begin{array}{l}\text { Densidad } \\
\text { aparente } \\
(\mathrm{gm} / \mathrm{ml})\end{array}$ & 0.85 & 0.80 & 0.82 & 0.83 & 0.82 \\
\hline $\begin{array}{l}\text { Capacidad de } \\
\text { absorción }(\%)\end{array}$ & 31.60 & 30.10 & 30.16 & 3019 & 31.00 \\
\hline $\begin{array}{l}\text { Velocidad de } \\
\text { infiltración } \\
\text { segundos }\end{array}$ & 6 & 5 & 5 & 5 & 5 \\
\hline Humedad (\%) & 46.29 & 46.60 & 46.58 & 46.00 & 50.00 \\
\hline $\begin{array}{l}\text { Tamaño } \\
\text { partículas } \\
(\mathrm{mm})\end{array}$ & 14 & 10 & 14 & 13 & 15 \\
\hline
\end{tabular}

Cuadro 2 Resultados de las variables físicas de las diferentes compostas tipo Bocashi y la vermicomposta

\begin{tabular}{|c|c|c|c|c|c|}
\hline $\begin{array}{c}\text { Propiedades } \\
\text { químicas }\end{array}$ & Bovino & Cerdo & Ovino & Conejo & $\begin{array}{c}\text { Vermi } \\
\text { composta }\end{array}$ \\
\hline $\begin{array}{l}\text { Materia } \\
\text { orgánica (\%) }\end{array}$ & 20.40 & 27.88 & 27.46 & 27.49 & 8.30 \\
\hline Nitratos $(\mathrm{mg} / \mathrm{kg})$ & 30.50 & 57.82 & 57.37 & 57.19 & 32.25 \\
\hline Fósforo $(\mathrm{mg} / \mathrm{kg})$ & 300.00 & 498.00 & 489.00 & 490.00 & 354.60 \\
\hline Potasio $(\mathrm{mg} / \mathrm{kg})$ & 10,320 & 10,380 & 10,286 & 10,282 & 10.460 . \\
\hline Calcio (mg/kg) & 79.25 & 75.96 & 74.91 & 75.19 & 39.85 \\
\hline $\begin{array}{l}\text { Magnesio } \\
(\mathrm{mg} / \mathrm{kg})\end{array}$ & 1,200 & 1,925 & 1,920 & 1,919 & 1.568 \\
\hline Sodio $(\mathrm{mg} / \mathrm{kg})$ & 22.98 & 18.10 & 20.89 & 21.56 & 21.19 \\
\hline Cobre $(\mathrm{mg} / \mathrm{kg})$ & 1.03 & 0.98 & 0.85 & 1.02 & 0.89 \\
\hline Hierro $(\mathrm{mg} / \mathrm{kg})$ & 1.00 & 1.00 & 1.01 & 1.08 & 1.28 \\
\hline $\begin{array}{l}\text { Manganeso } \\
(\mathrm{mg} / \mathrm{kg})\end{array}$ & 31.69 & 32.00 & 31.10 & 29.00 & 34.30 \\
\hline Zinc $(\mathrm{mg} / \mathrm{kg})$ & 2.99 & 2.89 & 2.74 & 2.81 & 1.38 \\
\hline Boro $(\mathrm{mg} / \mathrm{kg})$ & 4.39 & 0.44 & 3.60 & 3.21 & 3.19 \\
\hline $\mathrm{CO}_{3}$ & 7.85 & 7.84 & 7.84 & 7.83 & 7.03 \\
\hline $\mathrm{SO}_{4}$ & 10,000 & 10,003 & 10,000 & 10,001 & 10.005 \\
\hline $\mathrm{pH}$ & 8.27 & 8.47 & 8.09 & 8.37 & 8.26 \\
\hline $\begin{array}{l}\text { Conductividad } \\
\text { eléctrica Ds/cm) }\end{array}$ & 1.50 & 1.46 & 1.51 & 1.49 & 6.20 \\
\hline
\end{tabular}

Cuadro 3 Resultados químicos de las compostas tipo Bocashi y la vermicomposta

Variables biológicas, bioensayo de germinación de semilla y sobrevivencia. Los resultados para evaluar el bioensayo en germinación y sobrevivencia de las semillas de cebolla y chile en el sustrato muestreado, El análisis de la varianza muestra diferencia significativa para el efecto de tratamientos, en tanto que la prueba de separación de medias (DMS P>0.05), se muestra en el cuadro 4.
De acuerdo a lo mencionado por Polprasert (1989), en la fase de maduración se lleva a cabo una segunda fermentación que favorece la humificación, a partir de la transformación de varios complejos orgánicos a coloides húmicos estrechamente relacionados con minerales como el $\mathrm{Fe}, \mathrm{Ca}, \mathrm{N}$, etc., y finalmente a humus. Otro evento importante que se registra en esta fase son las reacciones de nitrificación, donde el amonio $\left(\mathrm{NH}_{4}{ }^{+}\right)$es biológicamente oxidado a nitrito $\left(\mathrm{NO}_{2}^{-}\right)$y finalmente a nitrato $\left(\mathrm{NO}_{3}^{-}\right)$.

El experimento de germinación de la semilla de rábano se repitió, pero ahora tomando una muestra de la pila de composta en la fase de maduración. El análisis de la varianza para esta variable, no presentó diferencias significativas para el efecto de tratamientos. El tratamiento testigo presento el $86.6 \%$ de germinación, cifra superior a la germinación lograda por los tratamientos con composta granulada de la parte alta y media de la pila ( $80 \%$ en ambos casos). Los tratamientos que lograron mayor porcentaje de germinación fueron el extracto de la parte media y baja de la pila, así como la composta granular de la porción baja de la composta (Cuadro 4).

\begin{tabular}{|c|c|c|c|c|}
\hline \multirow{2}{*}{$\begin{array}{l}\text { Diferentes tipos de } \\
\text { composta }\end{array}$} & \multicolumn{2}{|c|}{$\%$ de germinación } & \multicolumn{2}{|c|}{ \% de sobrevivencia } \\
\hline & S. chile & S. cebolla & S. chile & S. cebolla \\
\hline Composta de Bovino & $86^{\mathrm{b}}$ & $87^{b}$ & $88^{\mathrm{b}}$ & $89^{b}$ \\
\hline Composta de ovino & $86^{\mathrm{b}}$ & $88^{\mathrm{b}}$ & $88^{\mathrm{b}}$ & $86^{\mathrm{b}}$ \\
\hline Composta de cerdo & $92^{\mathrm{a}}$ & $90^{\mathrm{a}}$ & $90^{\mathrm{a}}$ & $93^{2}$ \\
\hline Composta de conejo & $90^{\mathrm{a}}$ & $91^{\mathrm{a}}$ & $92^{\mathrm{a}}$ & $91^{\circ}$ \\
\hline Vermicomposta & $90^{\mathrm{a}}$ & 89 & $91^{\mathrm{a}}$ & $88^{\mathrm{b}}$ \\
\hline Testigo arena & $75^{\mathrm{c}}$ & $76^{c}$ & $87^{\mathrm{b}}$ & $86^{\mathrm{b}}$ \\
\hline
\end{tabular}

*Promedios con distinta letra son estadísticamente diferentes (DMS P>0.05)

Cuadro 4 Porcentaje de germinación de los tratamientos estudiados

Conteo de microorganismos, la cuantificación en placa de hongos, bacterias y actinomicetos se determinaron durante la fase de maduración de la pila, la cuenta de hongos, actinomicetos y bacterias permaneció relativamente constante: $37 \times 10^{-2}, 10 \times 10^{-3}$ y $12 \times 10^{-6}$ UFC respectivamente, en el mismo periodo (cuadro 5). Durante la fase de madurez se desarrollan importantes procesos tales como la estabilización de la materia orgánica, que implica la atenuación de núcleos tóxicos generados durante la fermentación, la humificación y la nitrificación, entre otras. 
Este cambio es conducido principalmente por microorganismos, por lo que la actividad microbiana detectada en esta fase, puede estar relacionada a dichos cambios

\begin{tabular}{|lr|r|r|r|}
\hline \multicolumn{1}{|c}{ Muestra } & \multicolumn{1}{c}{$\begin{array}{c}\text { Hongos } \\
\text { (UFCX10- }\end{array}$} & $\begin{array}{c}\text { Actinomicetos } \\
\text { (UFCX10-3) }\end{array}$ & $\begin{array}{c}\text { Bacterias } \\
\text { (UFCX10- } \\
\text { 2) }\end{array}$ \\
\hline $\begin{array}{l}\text { Composta } \\
\text { bovino }\end{array}$ & de & 37 & 7 & 6 \\
\cline { 2 - 4 } $\begin{array}{l}\text { Composta } \\
\text { ovino }\end{array}$ & de & 36 & 10 & 12 \\
\cline { 2 - 4 } $\begin{array}{l}\text { Composta de } \\
\text { cerdo }\end{array}$ & 36 & 10 & 12 \\
\cline { 2 - 4 } $\begin{array}{l}\text { Composta } \\
\text { conejo }\end{array}$ & 35 & 8 & 10 \\
\hline $\begin{array}{l}\text { Vermi } \\
\text { composta }\end{array}$ & 37 & 7 & 7 \\
\cline { 2 - 4 } & 37 & 11 & 20 \\
\hline
\end{tabular}

Cuadro 5 Conteo de microorganismos evaluados en la composta

Evolución de $\mathrm{CO}_{2}$, la estabilidad valorada por respirometría, sirve para valorar la estabilidad relativa de los compuestos orgánicos de $\mathrm{C}$ presentes en una composta. La medición de $\mathrm{O}_{2}$ y $\mathrm{CO}_{2}$ de muestras de aire tomadas directamente de un montón en compostaje activo puede proporcionar datos para conocer las necesidades de aireación del montón (Haug, 1993). Los valores de $\mathrm{CO}_{2}$ (mg $\left.\mathrm{CO}_{2}\right)$ se determinaron durante la fase mesofílica y de maduración de la pila. La producción de $\mathrm{CO}_{2}$ permaneció constante entre los 4 y $5 \mathrm{mg} /$ día

\section{Conclusiones}

Con base en los resultados presentados anteriormente se puede concluir lo siguiente:

Los resultados de este estudio indican que la composta elaborada con cualquier tipo de residuo se puede utilizar como sustrato en semilleros de chile, cebolla o de otras hortalizas para inducir la germinación y acelerar el desarrollo de las plantas. Es posible probar la calidad de las compostas mediante pruebas directas de fitotoxicidad, lo cual nos permite hacer las recomendaciones para utilizarla como sustrato $\mathrm{o}$ en combinaciones con materiales inertes en semilleros a almácigos

En el bioensayo con la lombriz de tierra es posible señalar que la composta completó su fase de madurez, ya que la composta en estas condiciones no afectó el desarrollo de la lombriz y por su contenido húmico y características propias de madurez, no es posible que el organismo la utilizara como alimento.
En general se puede apreciar que la población de microorganismos presentes en la composta en la fase de maduración, los hongos fue la población dominante, en tanto que los valores de $\mathrm{CO}_{2}\left(\mathrm{mg} \mathrm{CO} \mathrm{CO}_{2}\right)$ se consideran como estables para evaluar la madurez de la composta. Dado que un decaimiento en la cantidad $\mathrm{CO}_{2}$ indicara la disminución de la actividad microbiana y con ello un retardo en el proceso de la descomposición de la materia orgánica.

La capacidad de absorción de agua, presento un porcentaje superior al rango recomendado como medio de sustrato. En este mismo sentido, la capilaridad, la velocidad de infiltración, así como la densidad aparente, presentaron valores dentro de los rangos recomendados de las propiedades fisicas de la composta para fines agrícolas

El valor de la absorbencia es una variable útil en la determinación de la madurez de la composta. Los valores disminuyen conforme la composta avanza en el proceso de maduración.

La conductividad eléctrica final se ubicó dentro de norma.

$\mathrm{Si}$ bien la cantidad de nutrientes encontrados en la composta no son tan altos, estos cumplen con los requerimientos mínimos de las normativas para ser utilizado como sustrato en aplicaciones hortícolas.

Los objetivos planteados en este trabajo se cumplieron en su totalidad.

\section{Referencias}

Ansorena, M.J. 1994. Sustratos. Propiedades y caracterización, Ediciones Mundi-Prensa, España, pp. 172.

Cadahia, C. 2005. Fertirrigación. Cultivos hortícolas, frutales y ornamentales, Tercera edición, Ediciones Mundi-Prensa, España, pp. 301-322.

U.S. Composting Council. 2001. Test methods for the examination of composting and compost, USDA-Compost Council.

Dalzel, H.W. 1991. Manejo del suelo. Producción y uso del compost en ambientes tropicales y subtropicales, Boletín de Suelos de la FAO, No. 56, Roma Italia, pp. 18-20. 
De Luna, V.A. y E.A. Vázquez. 2009. Elaboración de abonos orgánicos, Segunda edición, Universidad de Guadalajara, México, pp. 86.

Instituto Nacional de Normalización. 2005. Norma chilena oficial para el control de la calidad de compostas (NCh-2880.Of2004), Decreto exento no. 89, Chile.

Labrador, M.J. 2002. La materia orgánica en los agroecosistemas, Segunda Edición, Ediciones Mundi-Prensa, Madrid España, pp. 174.

Lampkin, N. 1998. Agricultura ecológica, Gestión de los estiércoles y residuos orgánicos, Ediciones Mundi Prensa, México D.F., pp. 85104.

Nieto, G.A. 2002. La composta. Importancia, elaboración y uso agrícola, Centro de Investigaciones Biológicas del Noroeste, La Paz B.C.S., México, pp. 86.

Haug T. Roger, 1993, The practical handbook of compost engineering, Publishers Lewis, Florida E.U.A., pp. 399.

Padrón, C.E. 2003. Diseños experimentales con aplicación a la agricultura y la ganadería, Primera reimpresión, Editorial Trillas, pp. 55-59

Reyes, C.P. 1999. Diseño de experimentos aplicados, Editorial Trillas, Tercera edición, pp. 122-128.

Rodríguez, S.M. y V.A. Córdova. 2006. Manual de compostaje municipal, tratamiento de residuos sólidos urbanos, Talleres $\mathrm{S}$ y $\mathrm{G}$ editores, Ciudad de México, pp. 102.

Simpson, K. 1991. Abonos y estiércoles, Acribia S.A., Zaragoza España, pp. 273.

Triano Sánchez Arnulfo, Palma López David Jesús y Hernández Nataren Edith, 2005, Uso de sustratos orgánicos y reciclaje de nutrimentos en la producción de cacao (Theobroma cacao L.) en el municipio de Cuanduacan Tabasco, Colegio de Posgraduados de Ciencias Agrícolas, Fundación Produce Tabasco A.C., Cárdenas Tabasco.
Valdés, R. 1980. Manual de Microbiología Agrícola, Instituto Politécnico Nacional, Escuela Nacional de Ciencias Biológicas, Departamento de Microbiología, Laboratorio de Microbiología Agrícola, pp. 69.

Zañudo, H.J., E.B. Pimienta y H.B. Ramírez. 2003. Manual de prácticas de fisiología vegetal, Academia de ecofisiología vegetal, Universidad de Guadalajara, Zapopan Jalisco, México,pp.86. 